\title{
The impact of social activities, social networks, social support and social relationships on the cognitive functioning of healthy older adults: a systematic review
}

Michelle E. Kelly ${ }^{1 *}$ (D) Hollie Duff' ${ }^{2}$ Sara Kelly ${ }^{2}$, Joanna E. McHugh Power ${ }^{1}$, Sabina Brennan ${ }^{3}$, Brian A. Lawlor ${ }^{4}$ and David G. Loughrey²

\begin{abstract}
Background: Social relationships, which are contingent on access to social networks, promote engagement in social activities and provide access to social support. These social factors have been shown to positively impact health outcomes. In the current systematic review, we offer a comprehensive overview of the impact of social activities, social networks and social support on the cognitive functioning of healthy older adults (50+) and examine the differential effects of aspects of social relationships on various cognitive domains.

Methods: We followed PRISMA (Preferred Reporting Items for Systematic Reviews and Meta-Analysis) guidelines, and collated data from randomised controlled trials (RCTs), genetic and observational studies. Independent variables of interest included subjective measures of social activities, social networks, and social support, and composite measures of social relationships (CMSR). The primary outcome of interest was cognitive function divided into domains of episodic memory, semantic memory, overall memory ability, working memory, verbal fluency, reasoning, attention, processing speed, visuospatial abilities, overall executive functioning and global cognition.

Results: Thirty-nine studies were included in the review; three RCTs, 34 observational studies, and two genetic studies. Evidence suggests a relationship between (1) social activity and global cognition and overall executive functioning, working memory, visuospatial abilities and processing speed but not episodic memory, verbal fluency, reasoning or attention; (2) social networks and global cognition but not episodic memory, attention or processing speed; (3) social support and global cognition and episodic memory but not attention or processing speed; and (4) CMSR and episodic memory and verbal fluency but not global cognition.

Conclusions: The results support prior conclusions that there is an association between social relationships and cognitive function but the exact nature of this association remains unclear. Implications of the findings are discussed and suggestions for future research provided.
\end{abstract}

Systematic review registration: PROSPERO 2012: CRD42012003248.

Keywords: Systematic review, Meta-analysis, Social relationships, Social activity, Social engagement, Cognitive function, Executive function, Working memory, Healthy older adults

\footnotetext{
* Correspondence: Michelle.Kelly@ncirl.ie

${ }^{1}$ Department of Psychology, School of Business, National College of Ireland,

2nd Floor, Mayor Street, IFSC, Dublin 1, Ireland

Full list of author information is available at the end of the article
} 


\section{Background}

Cognitive functioning plays an important role in determining functional abilities, quality of life and independence in older adults $[1,2]$. Although changes in cognitive function such as processing speed, episodic memory and executive functions are typical with normative cognitive ageing [3-5], cognitive decline is not a part of healthy ageing [6-8]. Evidence suggests that cognitive function in older adults may be affected by modifiable risk and protective factors including smoking, poor diet, levels of physical activity, cognitive stimulation and social relationships [9-13]. With an increasing ageing population, cognitive ageing researchers are prioritising exploration of these lifestyle factors as they may provide a pathway to interventions to prevent cognitive decline or maintain cognitive function in older adults. Of these lifestyle factors, social relationships are of particular interest as improving factors associated with social relationships may offer a relatively simple method of promoting positive outcomes in cognitive functioning.

One difficulty when trying to determine the effect of social relationships on cognitive function is the use of discrepant and unclear definitions of different social factors [14]. If researchers are to make accurate recommendations regarding activities that can promote cognitive health, they need to use precise terminology to ensure consistency and clarity of information presented. In an attempt to address the issue of discrepant definitions in the literature, Berkman and colleagues suggested a framework to clarify terms describing social factors and behaviours [15]. Berkman et al. explain that social integration, which includes upstream levels of social resources, community, and family, promotes access to social networks. Social networks, defined as "the web of social relationships that surrounds an individual" (p.847) in-turn facilitate engagement in social activities and access to social support [15]. Social relationships therefore, are both impacted by and influence social networks, social activity and social support [15-17]. Social network characteristics can include the network size, the relationship between members of the network, and the frequency of contact between network members [15]. Examples of social activity, also known as social participation or engagement, may include meeting friends, attending events or functions, volunteering or participating in occupational duties or group recreational activities [15]. Social support, often divided into emotional, instrumental, and informational support refers to a person's perception of the availability of help or support from others in their social network [15]. In two recent reviews, Kuiper and colleagues also refer to social relationships and explain that social networks and activity represent structural aspects of social relationships, while social support represents functional aspects of social relationships [18, 19]. In the interest of promoting the consistent use of well- defined terminology across reviews, we will use the terms as presented by Berkman et al. and Kuiper et al., and refer to the overall category of social relationships which incorporates factors including social networks, activity and support.

Research examining the effects of social relationships on older adults' cognitive functioning most commonly assesses the frequency of engagement in social activities [20], followed by social network size/structure [21] and social support [22]. Cross-sectional studies examining the relationship between engagement in social activity and cognitive function have found that an active and socially engaged lifestyle is related to improved cognitive function in ageing [23, 24]. Results from observational studies investigating longitudinal associations between social relationships and older adults' cognitive function are not conclusive however [25]. While many observational studies have found that aspects of social relationships, such as social activity, are related to benefits in cognitive function $[9,17,21,26-29]$, others have failed to do so [30-33]. The lack of consistency across observational studies is further compounded by a lack of supportive evidence from randomised controlled trials (RCTs). In their literature review, Wang et al. searched for RCTs to supplement correlational data on social activity and cognitive function, but found none, thereby limiting the extent to which causal relationships could be inferred [2]. Since then, to our knowledge, no RCTs examining lifestyle factors and cognitive function have included any social factors as primary intervention targets. Perhaps this lack of RCTs results from difficulties translating aspects of social relationships into a measurable experimental design [34]. Nonetheless, some RCTs have included engagement in social activities as active control conditions [34, 35], but these have yet to be examined in the context of a systematic review.

Consideration should be given to possible effects that different aspects of social relationships may have on specific cognitive processes [36-38], as each unique outcome may result in differential effects on the trajectory of cognitive decline [39]. The literature has previously been criticised for not permitting an assessment of domain-specific effects of social relationships on cognition [36]. In response to this, Gow et al. examined the effects of social relationship factors on general cognitive ability, memory and processing speed and found that more social support was associated with better general cognitive abilities but not memory, and less social support was associated with slower processing speed; these associations were partly accounted for by symptoms of depression. Other studies have also reported that different aspects of social relationships can differentially impact cognitive functioning, and discrepancies between these factors can have clinically meaningful 
effects on cognitive function $[19,40]$ and incident dementia outcomes [18].

From a theoretical perspective, there is clear reason to expect an association between social relationship factors and cognitive outcomes. Social activities may include a type of cognitive stimulation, thus contributing to cognitive outcomes via the building of cognitive reserve [41]; cognitive reserve optimises cognitive performance through the recruitment of alternate brain networks and cognitive strategies to compensate for cognitive difficulties related to pathology [42, 43]. Social support in particular may impact cognitive outcomes via its buffering effect on stress [44]. Interacting with others in one's social network may influence cognitive outcomes because close social ties makes positive health behaviours more likely (social control hypothesis; [45]). An intriguing alternative hypothesis has been put forward by Adolphs who proposes that all cognition is intrinsically social in nature [46]. It is also reasonable to assume that different aspects of social relationships may affect cognitive domains in different ways. For example, reducing stress through social support is likely to benefit memory and executive functioning $[47,48]$, while social network interactions may indirectly benefit reasoning, attention and processing speed through encouraging health behaviours such as exercise $[12,49]$. A detailed investigated of how social relationships may affect different cognitive domains has yet to be conducted.

Few literature reviews provide a comprehensive overview of research on social relationships and cognitive function in older adults. Structural and functional aspects social relationships are not often differentiated or separately assessed [50], precluding any meaningful comment on their distinct contributions towards cognitive ageing. In addition, social factors tend to be considered alongside or as part of other lifestyle factors such as leisure or intellectual activity [41]; outcomes such as mortality, physical health, or dementia are included in lieu of cognitive function $[10,18]$; only specific aspects of social relationships are considered, such as social isolation [51]; or reviews do not include comprehensive systematic literature searches $[52,53]$. The findings from prior reviews have shown a positive effect of engagement in social activities on verbal fluency [53] and of 'socialisation' on overall cognitive function [54], but findings were inconclusive and terminology used was inconsistent. Two more recent reviews that used consistent, welldefined terminology and examined various aspects of social relationships found that poor social relationships were associated with an increased risk of cognitive decline [19] and dementia [18]. A comprehensive review has yet to be conducted that clarifies the effect of social relationships on the cognitive function (continuous outcome) of older adults.
The aim of the current review was to evaluate the association between different aspects of social relationships; specifically social activity, social networks, and social support, with the cognitive functioning of healthy older adults with no known cognitive impairment. This is the first review to include data from available RCTs and genetic (twin) studies alongside an updated summary of observational evidence. The review is also innovative in its attempt to account for the differential effects of various factors associated with social relationships on specific cognitive domains (Fig. 1).

\section{Methods}

\section{Search strategy}

PubMed, Medline and PsycInfo were searched to identify RCTs, observational, and twin studies written in English and published between January 2000 and January 2017. The original search was conducted in 2015, and was updated in 2017. Search terms included 'social activity', 'social engagement', 'social intervention,' 'leisure intervention', combined with 'cognition,' 'cognitive performance,' 'cognitive decline,' 'cognitive function' and 'healthy elderly', 'older adults' (see Additional file 1 for full search strategy). Database searches were supplemented by searches of Google Scholar and hand searches of the reference sections of relevant reviews and included studies. Titles and abstracts were screened to exclude articles that did not meet inclusion criteria. Full texts of remaining studies were then screened for eligibility by two independent reviewers. Disagreements were resolved through discussions with the review team (see Fig. 2). This review is part of a series of reviews aimed at examining the impact of non-pharmacological interventions of the cognitive functioning of healthy older adults $[12,13,56]$. The review series was registered with the PROSPERO International prospective register of systematic reviews in 2012 (CRD42012003248).

\section{Selection criteria}

We followed Preferred Reporting Items for Systematic Reviews and Meta-Analysis (PRISMA) guidelines. The following inclusion criteria were used: (1) peer-reviewed and academically published observational, RCT or twin studies that (2) investigated the impact of engagement in social activities, social networks or social support on cognitive function and (3) included a sample of community dwelling older adults (>50 years) with no known cognitive impairment. We excluded studies if participants had been diagnosed with any cognitive impairment, cardiovascular disease, or other significant medical, psychiatric or neurological problems; or studies that combined data from participants with cognitive function within the normal range with data from participants 


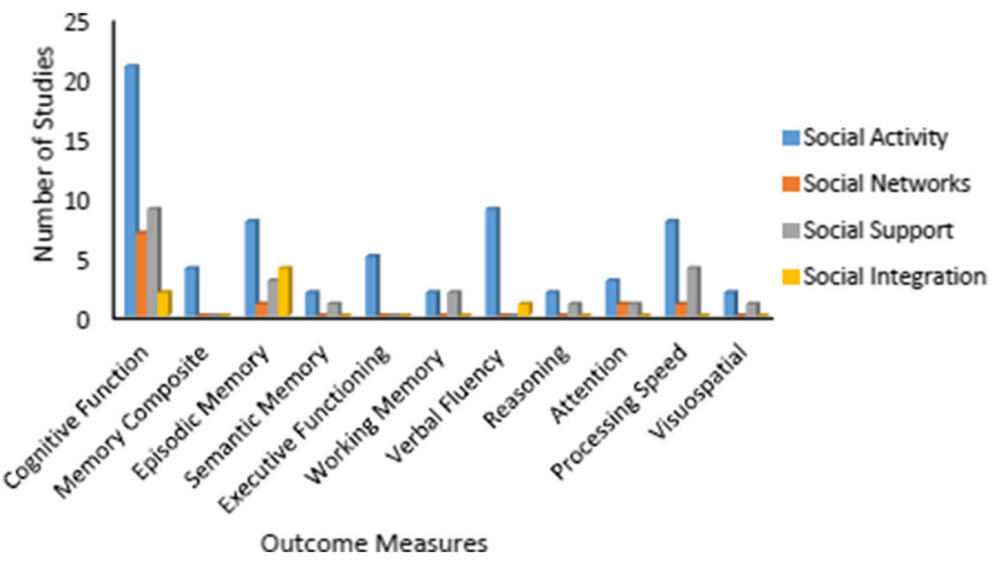

Fig. 1 The graph shows the total number of studies ( $y$-axis) that included outcome measures to assess cognitive abilities ( $x$-axis) for each of the four categories of social engagement (figure key)

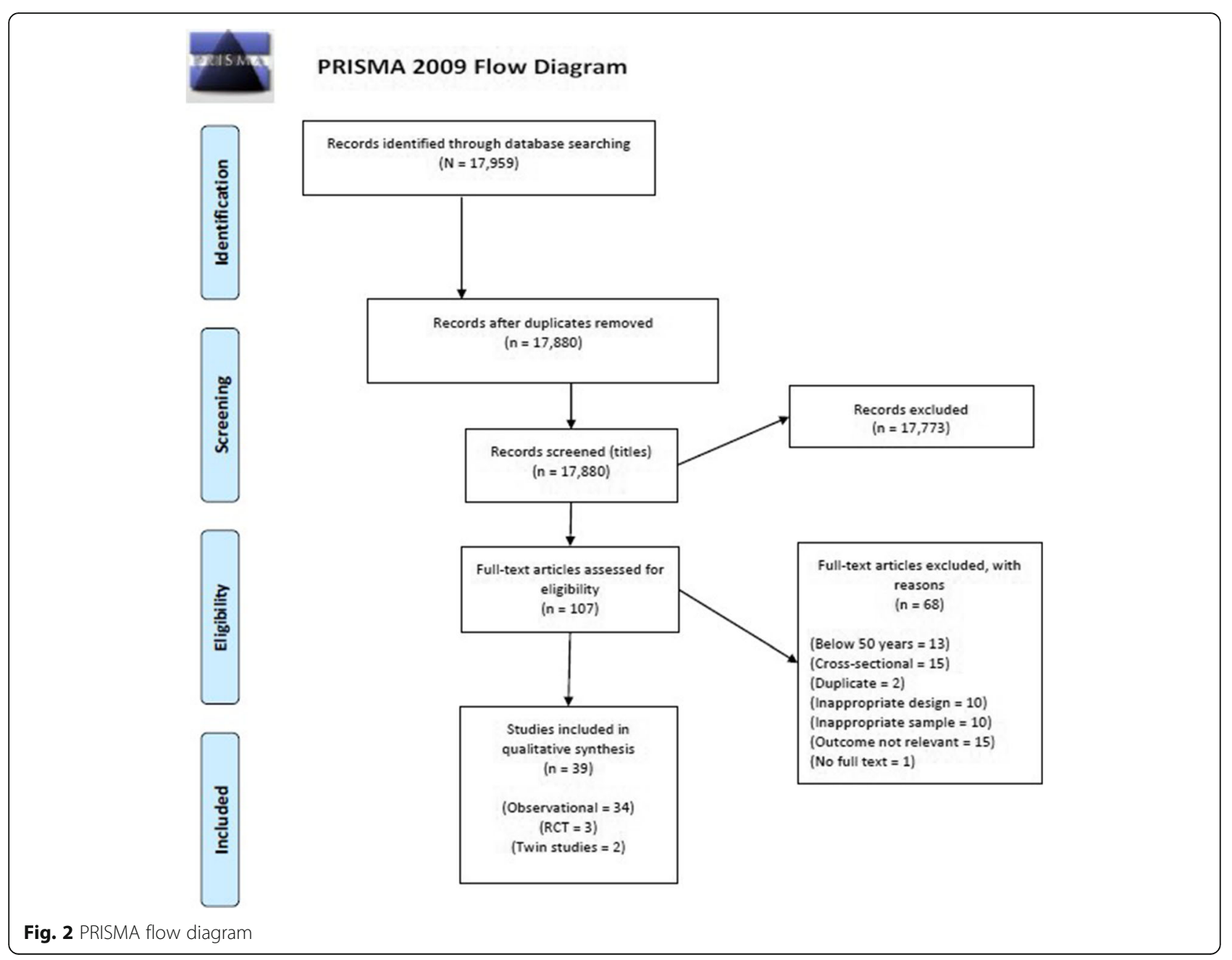


experiencing cognitive decline (see excluded studies table, Additional file 2).

\section{Outcomes of interest}

The primary outcome of interest was cognitive function. In line with a Cochrane review [55] and three prior reviews published by the review team [12, 13, 56], cognitive outcome measures were grouped into separate ability subgroups within the cognitive domains of memory and executive function. This permitted the comparison of data that was as homogenous as possible. Within the memory domain, outcomes were categorised to include measures of episodic memory, semantic memory or overall memory ability (measured by global or composite measures of memory). Within the executive function domain, outcomes were categorised to include measures of working memory, verbal fluency, reasoning, attention, processing speed, visuospatial abilities or overall executive functioning (measured by global or composite measures of executive function). Global cognition was measured using global or composite measures of cognitive function.

Social relationships were categorised based on the suggested framework of Berkman et al. [15] and included social activity, social networks, social support and composite measures of social relationships (CMSR). Social activity included engagement in facilitator led group discussions, social interactions, field trips, travel or outings, visiting and receiving visitors, participation in voluntary activities, religious activities, membership in community groups or associations, or attending social groups. Social networks included living arrangements, marital status, number of social ties or frequency of contact with friends and family. Social support included emotional support, satisfaction with support, positive or negative interactions, instrumental support, informational support, someone to share personal experiences and feelings with, help with decision making, support with daily tasks and general ratings of social support. Any combination of social activity, social networks and/or social support measures were considered as CMSR.

\section{Data extraction}

Data related to our outcomes of interest were extracted by two independent reviewers and cross-checked by an expert author. Cross-sectional and longitudinal outcomes were recorded that examined the relationship between social relationships and cognitive function. Multiple publication bias was avoided by using data from the most recently published study. Where two studies used data from the same cohort but presented different relevant outcomes, both were included on the same cell of the included studies table. Priority was given to outcomes that were adjusted for covariates/controlled for potential confounds. Due to large diversity between study' definitions and measurement of social relationships, cognitive outcomes measured, and analysis used, and in line with recommendations of from Section 9 of the Cochrane handbook, meta-analysis was not conducted as it was unlikely to derive meaningful conclusions. Guidelines from Section 8 of the Cochrane Handbook were used to assess risk of bias in RCTs (Additional file 3). The STROBE assessment tool was used to assess the quality of reporting in cohort studies (Additional file 4).

\section{Results}

Thirty-nine studies were identified that met the inclusion criteria outlined above; three RCTs including 576 participants, 34 observational studies including 87,509 participants in 32 longitudinal data sets, and two twin studies including 189 pairs of participants. Social activity was examined in three RCTs, 22 observational studies and two genetic studies; social networks and social support were examined in nine observational studies each, and CMSR were included in three observational studies. See Tables 1, 2, and 3. Social activity was the most common type of social relationship assessed and global/composite measures of cognitive function were the most common cognitive outcome measure employed. Overall, the type of social relationship and cognitive outcome measures included varied largely across studies (see Fig. 1).

\section{Randomised controlled trials/experimental findings}

Three RCTs assessed the impact of social activity on cognitive function with 21 cognitive test measures. Significant improvements were reported for social activity groups from baseline to follow-up on one (out of one) measure of verbal fluency [35]. Compared to a 'normal community care' control group, social activity improved performance on one out of three measures of global cognition [34, 35, 57]. Compared to active and placebo controls, non-significant trends for improvement were reported in domains of memory, episodic memory, processing speed, attention and visuospatial processing for engagement in social activity groups [34, 35]. Mortimer et al. also reported significant increases in brain volume in social activity compared to no intervention groups [35]. There were no improvements in performance for social activity groups on one measure of memory, two measures each of attention and processing speed and one measure of executive function [35].

\section{Observational/longitudinal studies Social activity}

Twenty-two observational studies examined the impact of social activity on cognitive function. At baseline, there were significant associations between social activity and higher scores on five out of five measures of global cognition [17, 58-60]; and one out of one measure each of 
Table 1 Characteristics of studies: intervention studies

\begin{tabular}{|c|c|c|c|c|c|}
\hline \multicolumn{6}{|c|}{ Intervention studies examining the impact of social relationships on cognitive function } \\
\hline Study & Participants & Intervention & Socialisation defined & $\begin{array}{l}\text { Cognitive outcome } \\
\text { measures }\end{array}$ & Results summary \\
\hline $\begin{array}{l}\text { Mortimer } \\
\text { (2012) [35] } \\
\text { China }\end{array}$ & $\begin{array}{l}N=120 \\
\text { 30/group } \\
\text { Age:60-79 }\end{array}$ & $\begin{array}{l}\text { 1. Tai Chi } \\
\text { 2. Walking } \\
\text { 3. Social activity } \\
\text { 4. No intervention } \\
3 \text { times/week, } \\
40 \text { weeks RCT }\end{array}$ & $\begin{array}{l}\text { Social activity: Meeting } \\
\text { and conversational } \\
\text { discussion facilitated by } \\
\text { leader and assistant } 3 \text { times } \\
\text { a week for } 40 \text { weeks. }\end{array}$ & $\begin{array}{l}\text { Memory } \\
\text { (composite AVLT, CVLT) } \\
\text { Attention (Bell Cancellation } \\
\text { Test, Stroop, TMT A) } \\
\text { Verbal Fluency (Category) } \\
\text { Executive function } \\
\text { (Rey CFT) } \\
\text { Processing speed } \\
\text { (WAIS Digit Span, } \\
\text { WAIS Similarities) } \\
\text { Cognitive function } \\
\text { (Boston Naming Test, } \\
\text { Clock-Drawing Test, MDRS) }\end{array}$ & $\begin{array}{l}\text { Baseline to } 40 \text {-week } \\
\text { follow-up; improved verbal } \\
\text { fluency }(p=0.01) \text {, trends for } \\
\text { improvement }(p<0.10) \text { on } \\
\text { TMT A and AVLT. } \\
\text { Increased brain volume in } \\
\text { the social interaction group } \\
\text { versus no intervention, } \\
(p<0.05) \text {. P-values not } \\
\text { provided for other } \\
\text { comparisons. }\end{array}$ \\
\hline $\begin{array}{l}\text { Park (2014) } \\
\text { [34] } \\
\text { USA }\end{array}$ & $\begin{array}{l}N=221 \\
\text { 1. } n=29 \\
\text { 2. } n=35 \\
\text { 3. } n=42 \\
\text { 4. } n=36 \\
\text { 5. } n=39 \\
\text { 6. } n=40 \\
\text { Age: } 60-90\end{array}$ & $\begin{array}{l}\text { Cognitive Engagement } \\
\text { 1. Photo group } \\
\text { 2. Quilt group } \\
\text { 3. Dual photo + quilt } \\
\text { control group } \\
\text { 4. Social activity } \\
\text { 5. Placebo } \\
\text { 6. No intervention } \\
\text { 15.9 h/week, } 14 \text { week } \\
\text { programme, Non-RCT }\end{array}$ & $\begin{array}{l}\text { Social activity: Participants } \\
\text { engaged in on-site, } \\
\text { facilitator-led social } \\
\text { interactions, field trips, } \\
\text { and entertainment with a } \\
\text { social group. }\end{array}$ & $\begin{array}{l}\text { Episodic memory } \\
\text { (Cantab, HVLT) } \\
\text { Visuospatial processing } \\
\text { (Cantab, Raven's } \\
\text { Progressive Matrices) } \\
\text { Processing speed } \\
\text { (Digit Span) } \\
\text { Attention/inhibitory control } \\
\text { (Flanker Task) } \\
\text { Cognitive function (MMSE) }\end{array}$ & $\begin{array}{l}\text { Social group showed } \\
\text { greater, but non-significant } \\
\text { pre-post-test improvements } \\
\text { versus photo, quilt and } \\
\text { placebo ( } p=0.10 \text { ) on } \\
\text { processing speed; photo } \\
\text { and placebo on attention/ } \\
\text { inhibitory control; placebo } \\
\text { on episodic memory; and } \\
\text { quilt, dual and placebo on } \\
\text { visuospatial processing. }\end{array}$ \\
\hline $\begin{array}{l}\text { Pitkala (2011) } \\
\text { [57] } \\
\text { Finland }\end{array}$ & $\begin{array}{l}N=235 \\
\text { 1. } n=117 \\
\text { 2. } n=118 \\
\text { Age: } 75+\end{array}$ & $\begin{array}{l}\text { 1. Social activity plus } \\
\text { therapeutic writing/group } \\
\text { exercise/art experience } \\
\text { 2. Normal community care } \\
6 \text { h/week, } 3 \text { months } \\
12 \text { month FU, RCT }\end{array}$ & $\begin{array}{l}\text { Social activity: Choice of } \\
1 / 3 \text { activities plus active } \\
\text { discussions, shared } \\
\text { experiences, discussed } \\
\text { feelings, peer support. } \\
\text { Facilitated by trained } \\
\text { professionals. }\end{array}$ & $\begin{array}{l}\text { Cognitive function } \\
\text { (ADAS-Cog) } \\
\text { Subjective Cognitive } \\
\text { Function }(15 D)^{b}\end{array}$ & $\begin{array}{l}\text { ADAS-Cog scores improved } \\
\text { significantly more in the } \\
\text { social group than in the } \\
\text { control group ( } p=0.023) \text {; } \\
\text { as did changes in 15D } \\
(p=0.047) \text {. }\end{array}$ \\
\hline
\end{tabular}

RCT randomised controlled trial, FU follow-up, AVLT Auditory Verbal Learning Test, CVLT Category Verbal Fluency Test, TMT Trail Making Test, Rey CFT Rey Complex Figure Task, WAIS- $R$ Wechsler Adult Intelligence Scale-Revised, MDRS Mattis Dementia Rating Scale, Cantab Cambridge Tests of Cognitive Function, HVLT Hopkins Verbal Learning Test, MMSE Mini Mental Status Examination, ADAS-Cog Alzheimer's disease Assessment Scale-Cognition Italic text indicates factors that were significantly related

${ }^{\text {a }}$ Significant improvement reported from baseline to follow-up

${ }^{b}$ Significant improvement reported in intervention compared to control

memory and working memory and verbal fluency [60]. At follow-up, significant associations were reported between social activity and performance on 12 out of 14 measures of global cognition [17, 21, 24, 30, 58, 61-70] one (out of one) composite memory measure [71], one (out of one) composite semantic memory measure [66]; four out of nine measures of episodic memory $[24,30,62$, $66,72,73]$; one out of four measures of executive function $[20,24,73]$; one out of one measure of working memory and visuospatial abilities [66]; three out of five measures of processing speed [30,37, 62, 66]; and one out of five measures of verbal fluency $[24,62,71-73]$. There were no associations between social activity and scores on two measures of reasoning [30, 73] and one measure of attention [62]. Hsu et al. [64] found that women with unpaid work at baseline were more likely to experience cognitive decline at follow-up; and Small et al. [38] reported that more social activity was related to poorer verbal fluency at follow-up.

\section{Social networks}

Nine observational studies examined the impact of social networks on cognitive function. Five studies examined network size and frequency of contact with members of the social network together $[17,61,63,74,75]$ and four studies examined network size alone [21, 32, 67, 76]. At baseline, social network size and frequency of contact were positively correlated with higher scores on measures of global cognition in two studies [17, 32]. At follow-up, six out of nine studies reported a significant association between social network size and frequency of contact with measures of global cognition [17, 21, $61,67,74,75]$. Two studies reported no association between social networks and global cognition [32, 63] and one reported no association between social network size and measures of episodic memory, attention, processing speed, or global cognition [76]. Number of social ties was not related to a global cognition in one study [32]. 


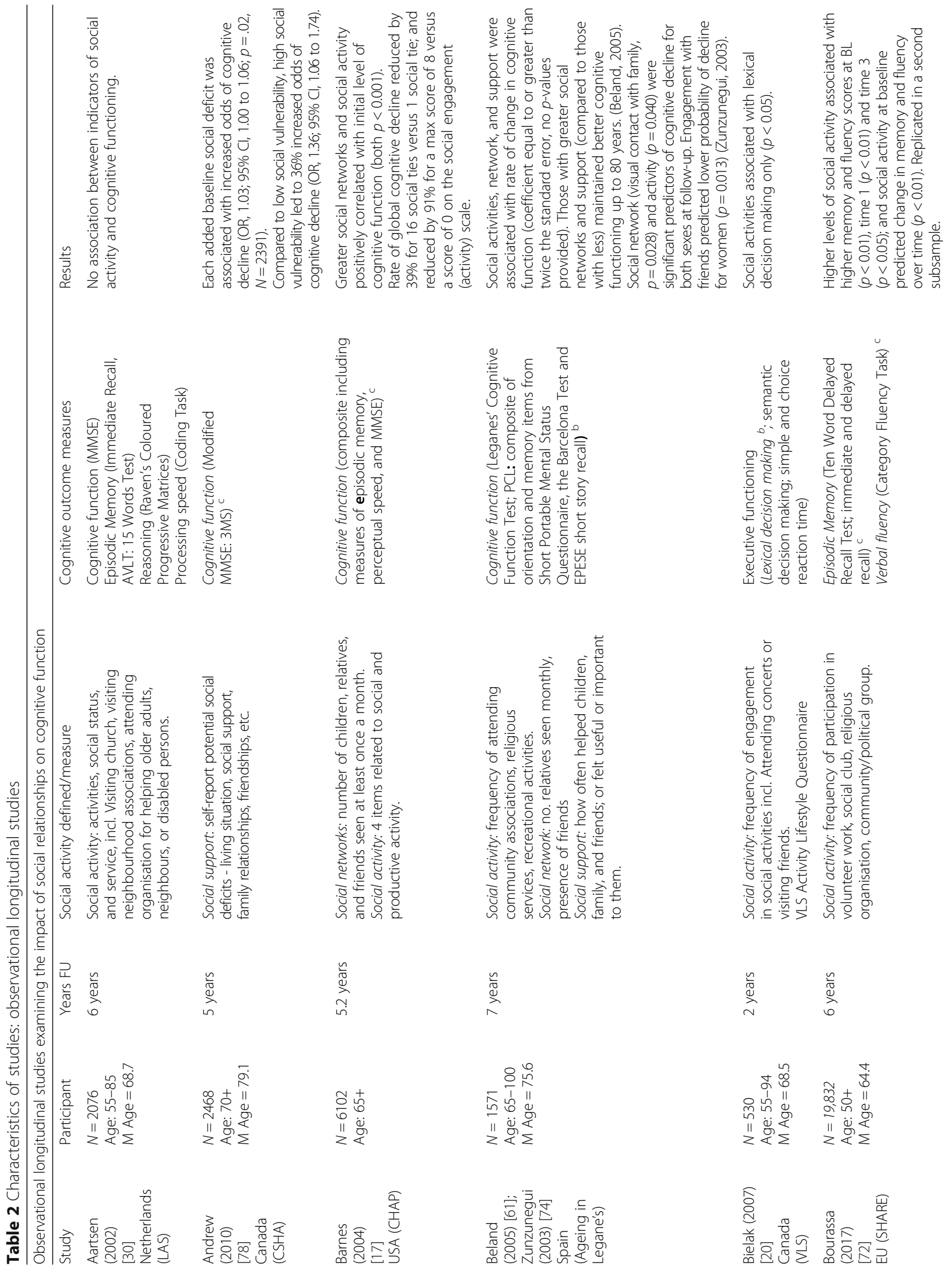




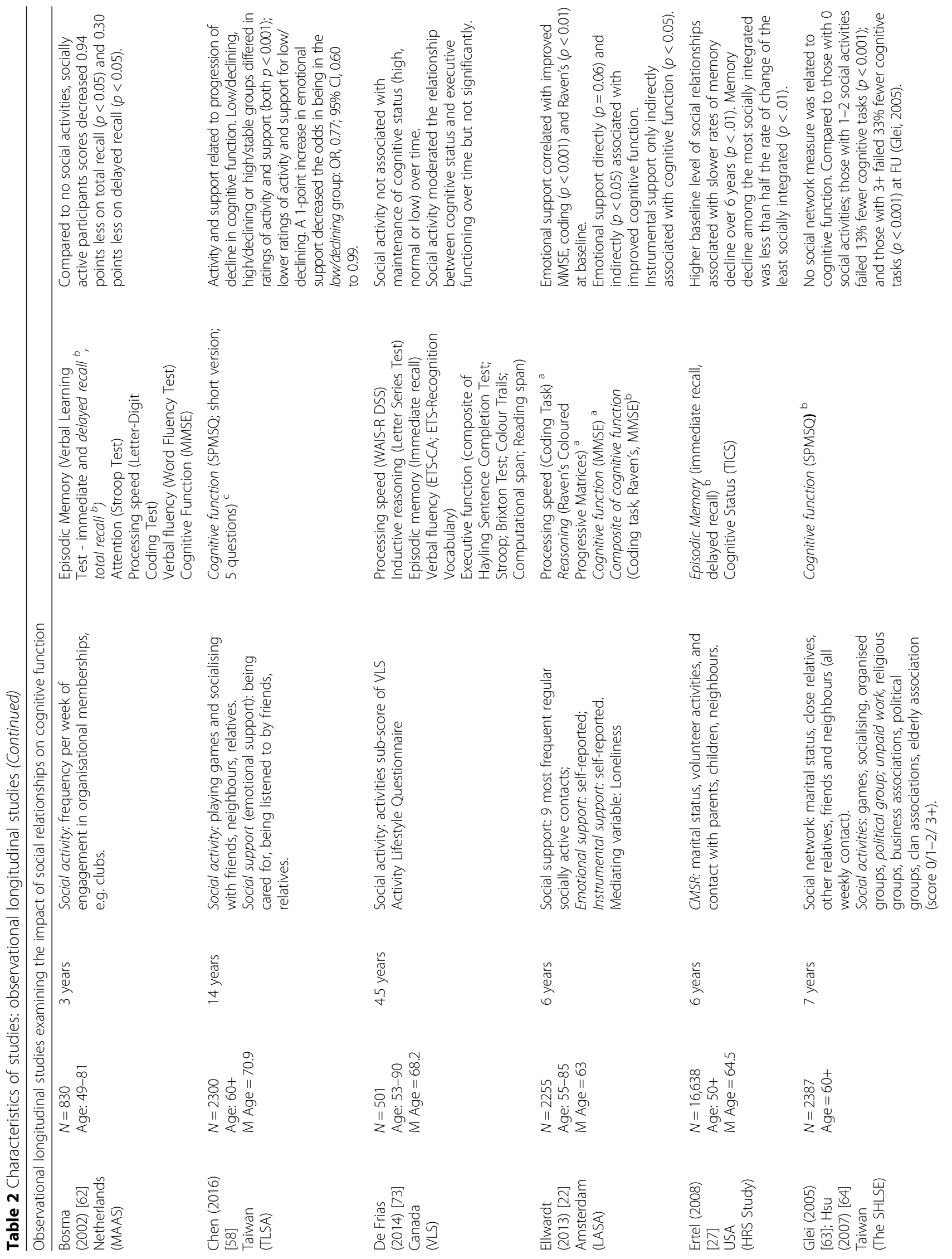




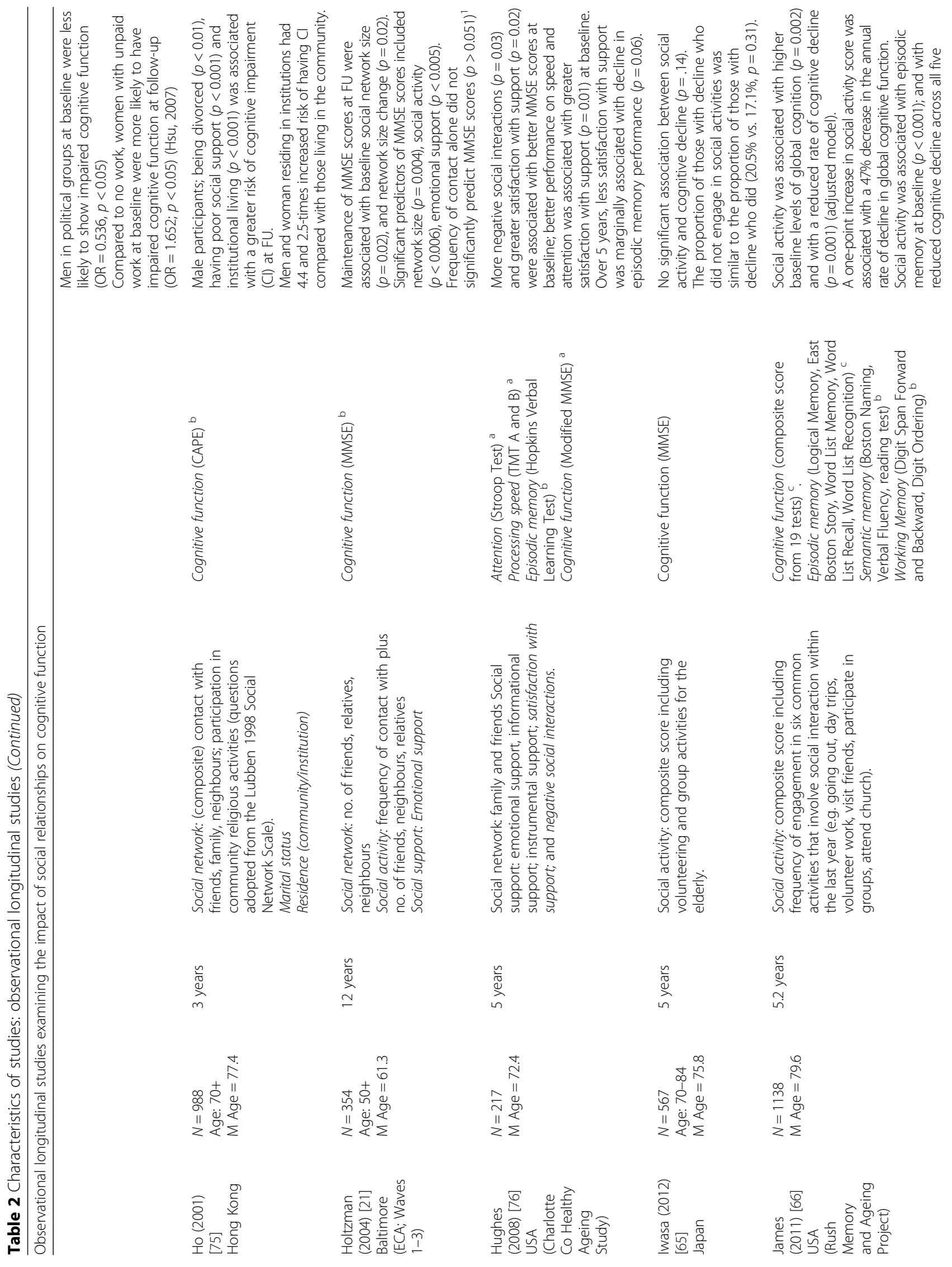




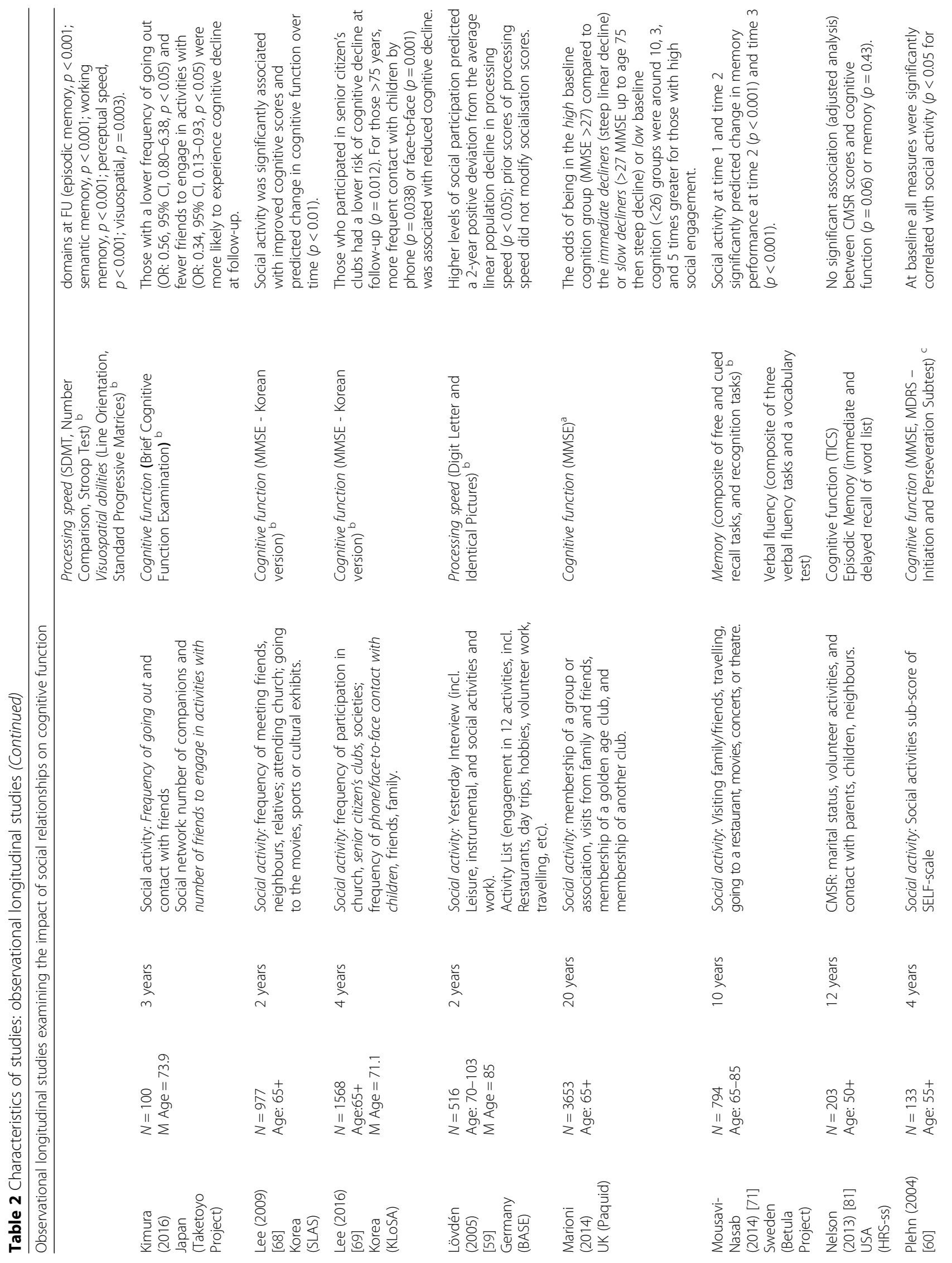




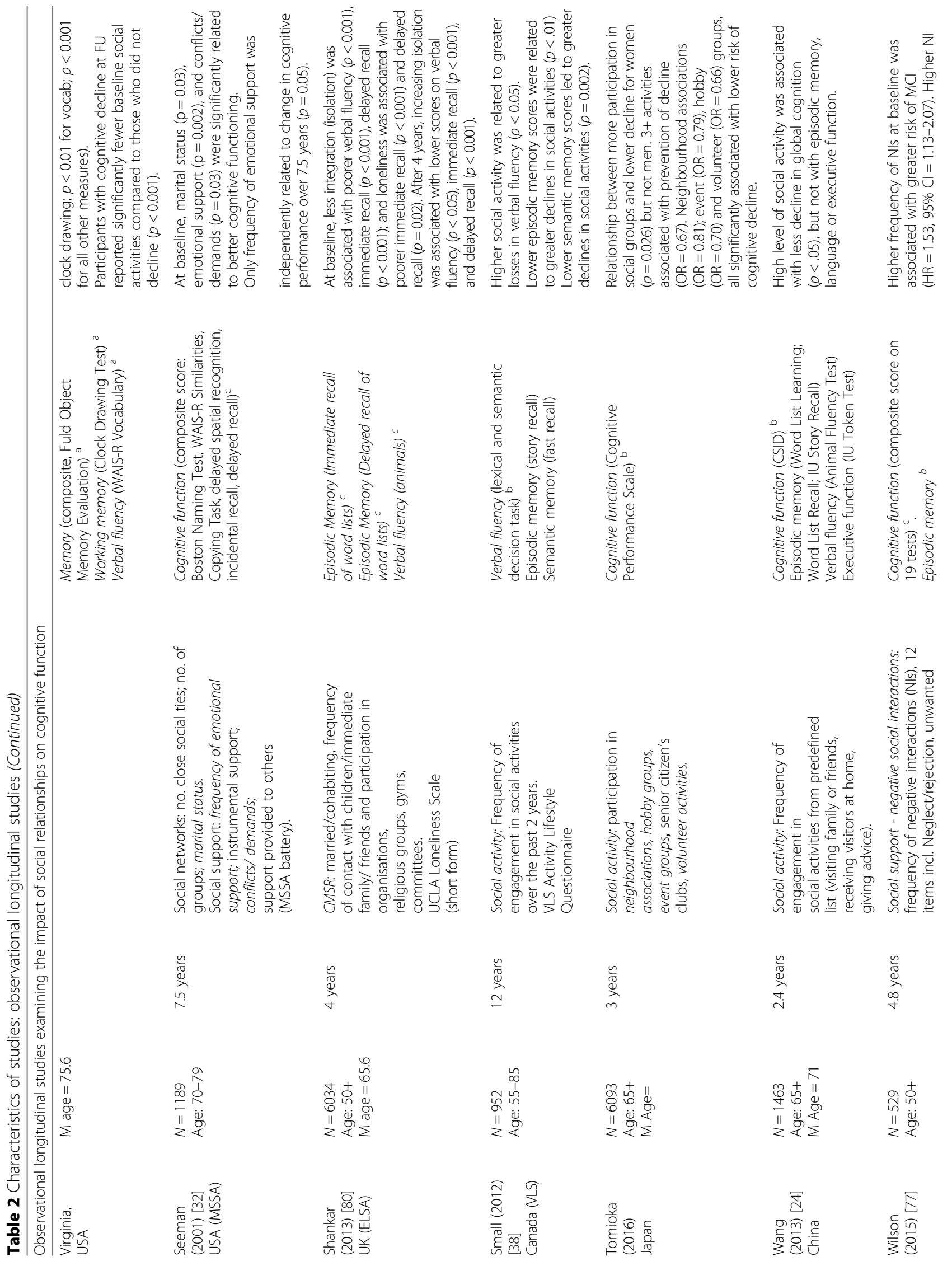




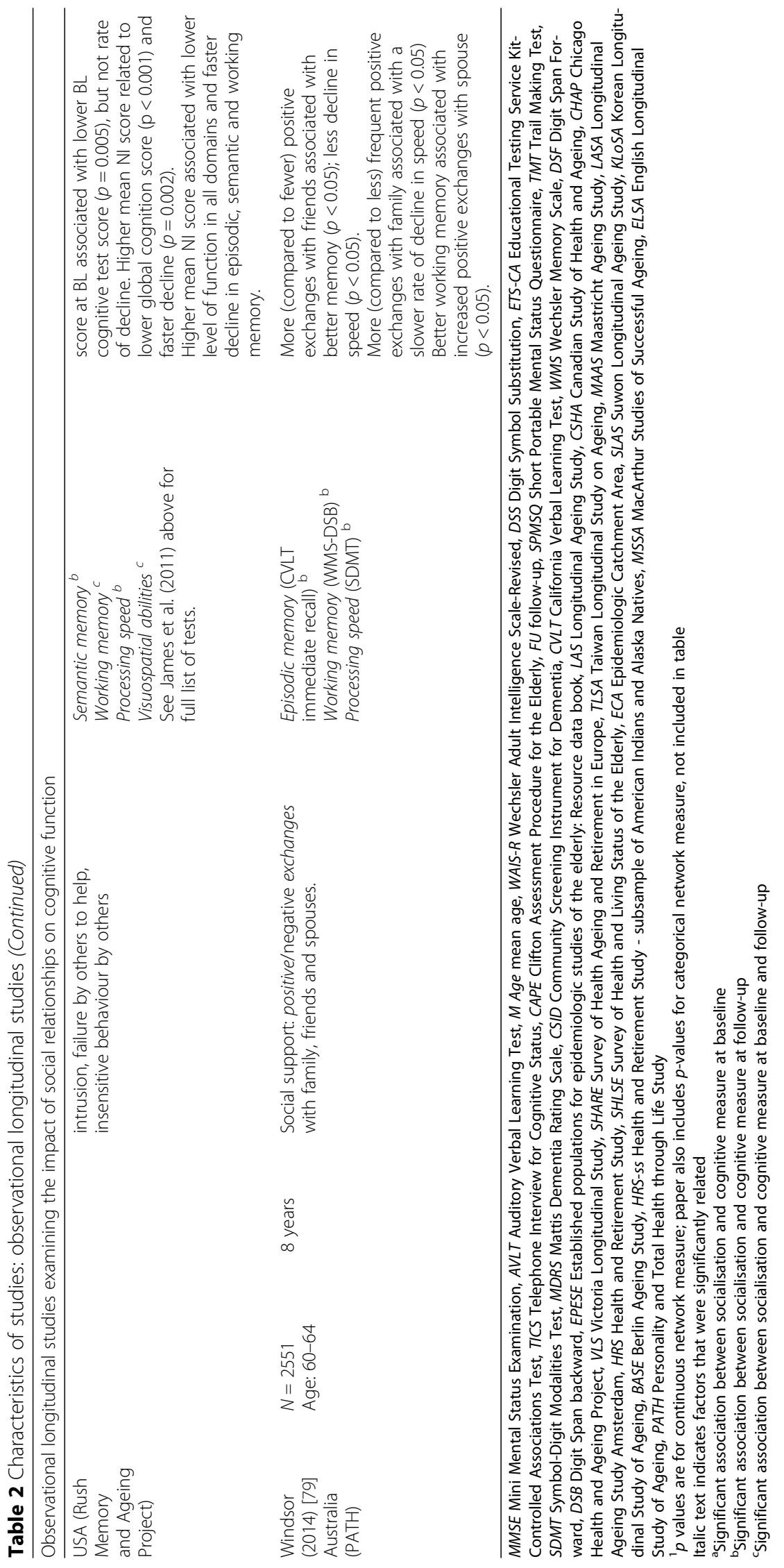


Table 3 Characteristics of studies: twin studies

\begin{tabular}{|c|c|c|c|c|c|}
\hline \multicolumn{6}{|c|}{ Twin studies examining the impact of social relationships on cognitive function } \\
\hline Study & Participants & Design & Social Activity Defined /Measure & Cognitive Outcome Measures & Results \\
\hline $\begin{array}{l}\text { Lee (2014) [84] } \\
\text { Australia }\end{array}$ & $\begin{array}{l}N=119 \text { pairs } \\
\text { of } \mathrm{MZ} \text { twins } \\
\text { Age: } 65+ \\
\mathrm{M} \mathrm{Age}=71\end{array}$ & $\begin{array}{l}\text { Discordant MZ } \\
\text { twin design }\end{array}$ & $\begin{array}{l}\text { Social activity: frequency of } \\
\text { engagement in social } \\
\text { activities incl. Contact family } \\
\text { member, neighbour, friends; } \\
\text { talk to neighbour; group } \\
\text { activities; church activities; } \\
\text { and voluntary work. } \\
\text { Adapted from the San } \\
\text { Diego Successful Ageing } \\
\text { Questionnaire. }\end{array}$ & $\begin{array}{l}\text { Memory (composite of } \\
\text { Logical Memory Story A, } \\
\text { RAVLT, BVRT) } \\
\text { Processing speed } \\
\text { (composite of TMT-A, Digit } \\
\text { Symbol Coding) } \\
\text { Verbal fluency (composite of } \\
\text { COWAT, Boston Naming Test) } \\
\text { Executive function } \\
\text { (composite of Digit Span } \\
\text { Backward, TMT-B/A, Stroop) } \\
\text { Cognitive function } \\
\text { (composite of four } \\
\text { cognitive domain scores) }\end{array}$ & $\begin{array}{l}\text { Statistically significant } \\
\text { association (controls } \\
\text { included) between } \\
\text { discordance scores for } \\
\text { social activity and memory } \\
(p=0.007) \text {. } \\
\text { No other associations } \\
\text { found for social activity. }\end{array}$ \\
\hline $\begin{array}{l}\text { McGue (2007) [82] } \\
\text { Denmark (LSADT) }\end{array}$ & $\begin{array}{l}N=70 \text { pairs } \\
M Z \text { twins } \\
M \text { Age }=77.4 \\
M \text { Age }=75.7\end{array}$ & $\begin{array}{l}\text { Discordant MZ } \\
\text { twin design }\end{array}$ & $\begin{array}{l}\text { Social activity: engaging with } \\
\text { others (leaving house, party) or } \\
\text { mental activity (engaging in a } \\
\text { hobby). } \\
\text { The Social Activity scale: } \\
\text { frequency engaged with others } \\
\text { and mental pursuits. }\end{array}$ & $\begin{array}{l}\text { Cognitive Function } \\
\text { (MMSE, composite measure) }\end{array}$ & $\begin{array}{l}\text { Social activity significantly } \\
\text { correlated with initial level } \\
\text { of cognitive functioning } \\
\text { ( } r=0.21 \text { for MMSE, } 0.44 \text { for } \\
\text { cognitive composite score). } \\
\text { Social activity was moderately } \\
\text { heritable ( } r=0.36) \text { Significant } \\
\text { association between } \\
\text { discordance scores and } \\
\text { cognitive composite score } \\
(p<0.001) \text { but not MMSE } \\
(p>0.25) \text {. }\end{array}$ \\
\hline
\end{tabular}

MZ monozygotic, RAVLT Rey Auditory Verbal Learning Test, BVRT Benson Visual Retention Test, TMT-A Trail Making Test-A, COWAT Controlled Oral Word Association Test, TMT-B/A ratio score of Trail Making Test B/Trail Making Test A, LSADT Longitudinal Study of Ageing Danish Twins, MMSE Mini Mental Status Examination

\section{Social support}

Nine observational studies examined the impact of aspects of social support on cognitive function. At baseline, there was a significant association between emotional support and improved outcomes on four out of five measures of global cognition [22, 32, 58, 76], one measure of reasoning and one measure of processing speed [22]. There were also significant positive associations at baseline between global cognitive function scores and satisfaction with support, negative interactions [76], and conflicts/demands [32]; and a conflicting negative association between baseline global cognition and negative interaction scores [77]. There were no baseline associations reported between instrumental support and scores on three measures of global cognition [22, 32, 76]; or measures of reasoning or processing speed [22]. There were no baseline associations reported between informational support [76] or support to others [32] and outcomes on measures of global cognition.

At follow-up, scores on measures of global cognition were positively correlated with social support [78]. Emotional support was associated with improvements on four out of five global cognition measures [21, 22, 32, 58, 76]. Satisfaction with social support was related to better episodic memory performance, but not attention, processing speed or global cognition [76]. Positive interactions were related to improvements on one out of three measures of episodic memory, one out of three measures of working memory, and two out of three measures of processing speed [79]. One out of three studies reported that negative interactions were related to lower scores on measures of global cognition, episodic memory, semantic memory, working memory, processing speed and visuospatial abilities [76, 77, 79]. Informational support and instrumental support were not related to scores on measures of episodic memory, working memory, attention, processing speed or global cognition in two studies [76, 79].

\section{Composite measures of social relationships}

Three studies examined the impact of social relationships on cognitive function. At baseline, lower scores on CMSR were associated with poorer verbal fluency and two (out of two) measures of episodic memory [80]. At follow-up, higher scores on CMSR were significantly related to better scores on four out of six measures of episodic memory [27, 80, 81]; and one measure of verbal fluency [80]. There was no reported association between CMSR and global cognition in two studies $[27,81]$.

\section{Genetic studies Social activity}

Two twin studies examined the impact of social activity on cognitive function. One study reported significant positive correlations between social activity and initial scores on two measures of global cognition [82]. Discordance scores showed significant associations between social 
activity and improved performance on one measure of memory [83] and on one out of three measures of global cognition [82, 83]. No associations were reported between social activity and outcomes on measures of executive function, verbal fluency or processing speed [83]. Social activity was found to be moderately heritable [82].

\section{Discussion}

Across the four distinct aspects of social relationships, evidence suggests a relationship between (1) social activity and global cognition, overall executive functioning, working memory, visuospatial abilities and processing speed but not episodic memory, verbal fluency, reasoning or attention; (2) social networks and global cognition but not episodic memory, attention or processing speed; (3) social support and global cognition and episodic memory but not attention or processing speed; and (4) CMSR and episodic memory and verbal fluency but not global cognition.

\section{Social activity}

In RCTs, social activity improved global cognition and increased brain volume but did not impact domains of memory, attention, verbal fluency, processing speed or overall executive functioning. Longitudinal associations were reported between social activity and global memory measures, overall executive functioning, working memory, visuospatial abilities, processing speed and global cognition but not episodic memory, verbal fluency, reasoning or attention. Genetic studies showed associations between social activity and memory and global cognition but not overall executive functioning, verbal fluency or processing speed.

Social activity was most consistently associated with improvements on global cognition, as measured by global or composite measures of cognitive function, across all study-types. This replication of results is encouraging, particularly since multiple studies investigated the impact of social activity on global cognition, and suggests that social activity may be useful for promoting brain health in older adults. The included longitudinal and genetic studies also showed that social activity was associated with some (i.e. working memory) but not all (i.e. verbal fluency) executive functioning domains. Although our results fail to support those of Brown et al. [53] who reported that social activity benefitted verbal fluency, the discrepancy may be explained by the number of studies included in each review. Our finding that social activity benefitted working memory supports research on social working memory (SWM) that describes working memory as essential for navigating the complexities of the social world [84], and suggests that this relationship is symbiotic. Additional research is required to examine the differential effects of social activity on specific domains of executive functioning, and to determine if social activity interventions can benefit cognitive function or prevent decline.

\section{Social networks, support and composite scores}

Similar to the findings for social activity, the results show that larger social networks and greater levels of social support were associated with improved global cognition. There were also differential effects of the type of social relationships on specific cognitive domains. Social support was associated with benefits to episodic memory but social activity and social networks were not. One explanation for differing effects of social support versus social activity and networks may be the impact that social support has on stress. Social support has been shown to promote resilience against the negative consequences of stress [85] whereas simply engaging in social activities or reporting a larger network of family and friends may not translate to the kind of social-emotional support required to obtain such stress-reducing benefits. Lower levels of stress has been shown to benefit memory and executive performance [47]. Negative interactions on the other hand, may increase stress and have a negative impact on overall cognitive function and on domains of episodic, semantic and working memory, processing speed and visuospatial abilities [76, 77, 79].

Social networks and activity are related concepts and both are structural dimensions of social relationships [85], and individuals who take part in more social activities tend to have a larger social networks (and vice versa). This would explain why social networks and activity appear to similarly impact cognitive domains. Social support on the other hand requires more than a quantity of friends/family and activities, it requires a functional dimension that provides both emotional and instrumental support [86]. This functional dimension is a better predictor of positive health outcomes than the quantitative dimension [87]. This supports ours and prior conclusions that there are distinct effects of different dimensions of social relationships on cognitive abilities [88, 89], and highlights the need for studies that are specifically designed to examine these specific effects. Intervention trials would also help to determine the precise aspects of social relationships that are needed to benefit cognitive function depending on the needs of at-risk older adults.

Scores on the outcome of CMSR were associated with verbal fluency but not global cognition and the findings regarding episodic memory and CMSR were inconsistent. It is difficult to draw any conclusions regarding CMSR because this composite score does not allow the determination of the differential effects of each specific social relationship-type. Future studies would benefit from ensuring consistency and specificity in defining and measuring distinct aspects of social relationships. 


\section{Cognitive decline and social relationships}

Overall, the results show that social relationships, as defined in this review, benefits older adults' cognitive functioning. Changes in the characteristics of social relationships could be a consequence of cognitive decline as opposed to a cause however [25]. The finding that episodic and semantic memory decline are related to a subsequent decline in social activity supports this view [38]. The stigma associated with cognitive decline may lead to social withdrawal [90], failing memory or word-finding difficulties may impede confidence and self-efficacy [91, 92] or poorer cognitive function might result in reduced ability to function socially [25].

Contradictory research has reported that cognitive decline and decline in perceptual speed does not predict decline in social relationships or function [37, 60], and episodic and semantic memory do not predict social activity [71]. In the latter study, while participants with and without cognitive decline both showed decline in social relationships, older individuals engaged in social activities to a lesser extent. Perhaps age may be more influential in affecting social relationships than cognitive decline [93]. Either way, the results demonstrate the complexities of the association between social relationships and older adults' cognitive function. It is most likely that there is a dual effect, explained by cognitive reserve whereby (1) higher level of engagement promotes positive cognitive outcomes and (2) higher levels of functioning is related to living a more engaged lifestyle $[38,41]$.

\section{Limitations and future directions}

We found it difficult to identify RCTs that included social relationships as either intervention or active control components. The search terms used may not have identified RCTs that focused on alternative lifestyle factors such as exercise that might have included social relationships as an active control condition, meaning that we may not have included all relevant RCTs. In addition, databases were only searched from the year 2000 to 2017, and Medical Subject Headings (MeSH) were not used meaning that some relevant studies may have been omitted. This was somewhat controlled for through supplemental searches of reference lists of included studies. The more pertinent issue is the fact that there are so few RCTs published that primarily focus on social interventions. This is most likely due to the difficulty in forming appropriate control conditions, although socially isolated older adults are not uncommon-however, they are, by their very nature, a difficult group to access for research. An RCT that recruited socially isolated older adults into four conditions: (1) social activity, (2) social networks; (3) social support; (4) wait-list control and examined outcomes on cognitive and social functioning measures would provide important insights.
The heterogeneity in definitions and measures of social relationships and cognitive function resulted in difficulties collating research evidence in a meaningful way and precluded us from conducting a meta-analysis. To promote homogeneity, future research could use the categorisation and definitions of social relationships as outlined in this review. Studies would benefit from an agreed appropriate battery of cognitive tests to be used when examining each distinct aspect of social relationships; for example, measures of episodic memory might be more important when investigating social support than networks or activity, and studies would benefit from including measures of global cognition and working memory for all social relationship-types. Systematic reviews consistently call for standardisation of tests measures to improve replicability and test the reliability of individual study findings, and yet standardisation and replication remain largely absent from this literature. Future RCT and longitudinal studies need to replicate prior studies with a view to strengthening existing evidence and determining the exact nature of the association between social relationships and cognitive function.

Exploring the impact of social relationships as distinct from cognitive, leisure or physical domains of activity is questionable, since all social behaviour includes aspects of these three domains of activity and it is not possible to isolate purely social factors. Many leisure activities have a physical (dancing, walking) or cognitive (playing chess) element which impact on cognitive processes and may confound measurement of social behaviour. To design effective RCTs, researchers could design interventions that include social activities, networks and support, and ensure these are clearly defined and consistently used across studies to improve comparability of results. It would also be helpful to avoid incorporating clear physical exercise or cognitive stimulation in social interventions which may confound results. Future research might also consider the impact of technology, internet and social media on social relationships, particularly feelings of social support.

Loneliness was not considered in the current review. While previous meta-analyses and reviews have investigated loneliness and social isolation together [94, 95], with regards to other outcomes, loneliness is often experienced as a psychological phenomenon which is not entirely contingent on social engagement but instead at least partly attributable to factors such as maladaptive social cognitions [96] and feelings of physical security [97]. As such, loneliness may not be suitable for inclusion in discussions concerning social relationships per se, although a detailed account of social support may describe loneliness where perceived social support is lacking. 


\section{Conclusions}

Researchers suggest that the size of the association between social relationships and cognition is similar to that of age and cognition [63, 72]. Our review adds to and supports existing research and findings show that there is an association between social relationships and the cognitive functioning of healthy older adults, although the specific nature of this association remains unclear. This review is novel in its examination of different aspects of social relationships, namely social activity, social networks, social support, and CMSR, and the differential effects these factors have on cognitive functioning. Evidence was most consistent in favour of a relationship between the distinct forms of social relationships and global cognition and working memory. It is important to reiterate the necessity to define social relationships more clearly to achieve homogeneity across studies [14, 40, 98]. Future research needs to achieve consistency in social and cognitive definitions and measures, replication of prior correlational findings, and the design of appropriate RCTs to provide a more thorough and meaningful investigation of the impact of social relationships on the cognitive functioning of healthy older adults.

\section{Additional files}

Additional file 1: Search results. Table of search terms and results as used in the systematic literature search. (DOCX $19 \mathrm{~kb}$ )

Additional file 2: Excluded studies. Table of studies excluded from the systematic review. (DOCX $28 \mathrm{~kb})$

Additional file 3: Risk of bias in RCTs. Table including information regarding the risk of bias assessment conducted on RCTs. (DOCX 18 kb)

Additional file 4: STROBE quality assessment. Table including information of the quality assessment conducted on all observational studies. (XLSX $16 \mathrm{~kb}$ )

\section{Abbreviations}

ADAS-Cog: Alzheimer's Disease Assessment Scale-Cognition; AVLT: Auditory Verbal Learning Test; BASE: Berlin Ageing Study; BVRT: Benson Visual Retention Test; Cantab: Cambridge Tests of Cognitive Function; CAPE: Clifton Assessment Procedure for the Elderly; CHAP: Chicago Health and Ageing Project; CMSR: Composite Measures of Social Relationships;

COWAT: Controlled Oral Word Association Test; CSHA: Canadian Study of Health and Ageing; CSID: Community Screening Instrument for Dementia; CVLT: California Verbal Learning Test; DSB: Digit span backward; DSF: Digit span forward; DSS: Digit symbol substitution; ECA: Epidemiologic catchment area; ELSA: English Longitudinal Study of Ageing; EPESE: Established Populations for Epidemiologic Studies of the Elderly; ETS-CA: Educational Testing Service Kit-Controlled Associations Test; FU: Follow-up; HRS: Health and Retirement Study; HRS-ss: Health and Retirement Study_-subsample of American Indians and Alaska Natives; HVLT: Hopkins Verbal Learning Test; KLoSA: Korean Longitudinal Study of Ageing; LAS: Longitudinal Ageing Study; LASA: Longitudinal Ageing Study Amsterdam; LSADT: Longitudinal Study of Ageing Danish Twins; M Age: Mean age; MAAS: Maastricht Ageing Study; MDRS: Mattis Dementia Rating Scale; MMSE: Mini Mental Status Examination; MSSA: MacArthur Studies of Successful Ageing; MZ: Monozygotic; PATH: Personality and Total Health Through Life Study; RAVLT: Rey Auditory Verbal Learning Test; RCTs: Randomised controlled trials; Rey CFT: Rey Complex Figure Task; SDMT: Symbol-Digit Modalities Test; SHARE: Survey of Health Ageing and Retirement in Europe; SHLSE: Survey of Health and Living Status of the Elderly; SLAS: Suwon Longitudinal Ageing
Study; SPMSQ: Short Portable Mental Status Questionnaire; STROBE: Strengthening the Reporting of Observational Studies in Epidemiology; TICS: Telephone Interview for Cognitive Status; TLSA: Taiwan Longitudinal Study on Ageing; TMT: Trail Making Test; TMT-A: Trail Making Test-A; TMT-B/A: Ratio Score of Trail Making Test B/Trail Making Test A; VLS: Victoria Longitudinal Study; WAIS-R: Wechsler Adult Intelligence Scale-Revised; WMS: Wechsler Memory Scale

\section{Acknowledgements}

We would like to thank Professor lan Robertson for his assistance in categorising cognitive tests and domains.

\section{Availability of data and material}

All relevant materials including search results, included and excluded studies tables, PRISMA flow diagram and risk of bias and quality assessments are included in this published article and its supplementary information files. Data extraction tables are available from the corresponding author on request.

\section{Funding}

The authors have not been funded to complete this review.

\section{Authors' contributions}

MK wrote the manuscript, updated literature searches, drafted tables and figures, contributed to the risk of bias and quality assessments and edited supporting files. HD and SK conducted literature searches, contributed to writing the manuscript, tables and supporting files, and assisted with the risk of bias and quality assessments. JEP contributed to writing the manuscript and edited the supporting files. SB contributed to the conception and design of the review, and edited the manuscript and supporting files. BL contributed to the conception and design of the review and reviewed the manuscript for important intellectual content. DL was responsible for overall supervision of the review, and contributed to data acquisition, risk of bias and quality assessments and editing the manuscript. All authors read and approved the final manuscript

\section{Ethics approval and consent to participate}

Not applicable

\section{Consent for publication}

Not applicable

\section{Competing interests}

The authors declare that they have no competing interests.

\section{Publisher's Note}

Springer Nature remains neutral with regard to jurisdictional claims in published maps and institutional affiliations.

\section{Author details}

${ }^{1}$ Department of Psychology, School of Business, National College of Ireland, 2nd Floor, Mayor Street, IFSC, Dublin 1, Ireland. ${ }^{2}$ The NEIL Programme, Institute of Neuroscience, Trinity College Dublin, Dublin 2, Ireland. ${ }^{3}$ ADAPT Centre, Trinity College Dublin, Dublin, Ireland. ${ }^{4}$ Global Brain Health Institute, Trinity College Dublin, Dublin, Ireland.

Received: 13 July 2017 Accepted: 20 November 2017

Published online: 19 December 2017

References

1. Cigolle CT, Langa KM, Kabeto MU, Tian Z, Blaum CS. Geriatric conditions and disability: the health and retirement study. Ann Intern Med. 2007;147(3):156-64.

2. Wang HX, Xu W, Pei JJ. Leisure activities, cognition and dementia. Biochim Biophys Acta. 2012;1822(3):482-91.

3. Craik FIM, Salthouse TA. The handbook of aging and cognition. 3rd ed. New York: Psychology Press; 2007

4. Small BJ, Dixon RA, McArdle JJ. Tracking cognition-health changes from 55 to 95 years of age. J Gerontol B Psychol Sci Soc Sci. 2011;66(Suppl 1):i153-61.

5. Lamar M, Resnick SM, Zonderman AB. Longitudinal changes in verbal memory in older adults: distinguishing the effects of age from repeat testing. Neurology. 2003;60(1):82-6. 
6. Fillit HM, Butler RN, O'Connell AW, Albert MS, Birren JE, Cotman CW, Greenough WT, Gold PE, Kramer AF, Kuller LH, et al. Achieving and maintaining cognitive vitality with aging. Mayo Clin Proc. 2002;77(7):681-96.

7. Stern PC, Carstensen LL. The aging mind: opportunities in cognitive research. Washington DC: National Academy Press; 2000.

8. Hertzog C, Kramer AF, Wilson RS, Lindenberger U. Enrichment effects on adult cognitive development: can the functional capacity of older adults be preserved and enhanced? Psychol Sci Public Interest. 2008;9(1):1-65.

9. Bassuk SS, Glass TA, Berkman LF. Social disengagement and incident cognitive decline in community-dwelling elderly persons. Ann Intern Med. 1999;131(3):165-73.

10. Fratiglioni L, Paillard-Borg S, Winblad B. An active and socially integrated lifestyle in late life might protect against dementia. Lancet Neurol. 2004;3(6):343-53.

11. Fratiglioni L, Qiu C. Prevention of cognitive decline in ageing: dementia as the target, delayed onset as the goal. Lancet Neurol. 2011;10(9):778-9.

12. Kelly ME, Loughrey D, Lawlor BA, Robertson $I H$, Walsh C, Brennan S. The impact of exercise on the cognitive functioning of healthy older adults: a systematic review and meta-analysis. Ageing Res Rev. 2014;16:12-31.

13. Kelly ME, Loughrey D, Lawlor BA, Robertson IH, Walsh C, Brennan S. The impact of cognitive training and mental stimulation on cognitive and everyday functioning of healthy older adults: a systematic review and metaanalysis. Ageing Res Rev. 2014;15:28-43.

14. Holt-Lunstad J, Smith TB, Layton JB. Social relationships and mortality risk: a meta-analytic review. PLoS Med. 2010;7(7):e1000316.

15. Berkman LF, Glass T, Brissette I, Seeman TE. From social integration to health: Durkheim in the new millennium. Soc Sci Med. 2000;51(6):843-57.

16. Bosc M. Assessment of social functioning in depression. Compr Psychiatry. 2000;41(1):63-9

17. Barnes LL, Mendes de Leon CF, Wilson RS, Bienias JL, Evans DA. Social resources and cognitive decline in a population of older African Americans and whites. Neurology. 2004;63(12):2322-6.

18. Kuiper JS, Zuidersma M, Oude Voshaar RC, Zuidema SU, van den Heuvel ER, Stolk RP, Smidt N. Social relationships and risk of dementia: a systematic review and meta-analysis of longitudinal cohort studies. Ageing Res Rev. 2015;22:39-57.

19. Kuiper JS, Zuidersma M, Zuidema SU, Burgerhof JG, Stolk RP, Oude Voshaar RC, Smidt N. Social relationships and cognitive decline: a systematic review and meta-analysis of longitudinal cohort studies. Int J Epidemiol. 2016;45(4): 1169-206.

20. Bielak AA, Hughes TF, Small BJ, Dixon RA. It's never too late to engage in lifestyle activities: significant concurrent but not change relationships between lifestyle activities and cognitive speed. J Gerontol B Psychol Sci Soc Sci. 2007;62(6):P331-9.

21. Holtzman RE, Rebok GW, Saczynski JS, Kouzis AC, Wilcox Doyle K, Eaton WW. Social network characteristics and cognition in middle-aged and older adults. J Gerontol B Psychol Sci Soc Sci. 2004;59(6):P278-84.

22. Ellwardt $L$, Aartsen M, Deeg D, Steverink N. Does loneliness mediate the relation between social support and cognitive functioning in later life? Soc Sci Med. 2013;98:116-24.

23. Litwin H, Stoeckel KJ. Social network, activity participation, and cognition: a complex relationship. Res Aging. 2016;38(1):76-97.

24. Wang HX, Jin $Y$, Hendrie HC, Liang C, Yang L, Cheng Y, Unverzagt FW, Ma F, Hall KS, Murrell JR, et al. Late life leisure activities and risk of cognitive decline. J Gerontol A Biol Sci Med Sci. 2013;68(2):205-13.

25. Green AF, Rebok G, Lyketsos CG. Influence of social network characteristics on cognition and functional status with aging. Int J Geriatr Psychiatry. 2008; 23(9):972-8

26. Newson RS, Kemps EB. General lifestyle activities as a predictor of current cognition and cognitive change in older adults: a cross-sectional and longitudinal examination. J Gerontol B Psychol Sci Soc Sci. 2005;60(3):P113-20.

27. Ertel KA, Glymour MM, Berkman LF. Effects of social integration on preserving memory function in a nationally representative US elderly population. Am J Public Health. 2008;98(7):1215-20.

28. Krueger KR, Wilson RS, Kamenetsky JM, Barnes LL, Bienias JL, Bennett DA. Social engagement and cognitive function in old age. Exp Aging Res. 2009:35(1):45-60.

29. Yeh SC, Liu YY. Influence of social support on cognitive function in the elderly. BMC Health Serv Res. 2003;3(1):9.

30. Aartsen MJ, Smits CH, van Tilburg T, Knipscheer KC, Deeg DJ. Activity in older adults: cause or consequence of cognitive functioning? A longitudinal study on everyday activities and cognitive performance in older adults. J Gerontol B Psychol Sci Soc Sci. 2002:57(2):P153-62.
31. Richards M, Hardy R, Wadsworth ME. Does active leisure protect cognition? Evidence from a national birth cohort. Soc Sci Med. 2003;56(4):785-92.

32. Seeman TE, Lusignolo TM, Albert M, Berkman L. Social relationships, social support, and patterns of cognitive aging in healthy, high-functioning older adults: MacArthur studies of successful aging. Health Psychol. 2001;20(4):243-55.

33. Kareholt I, Lennartsson C, Gatz M, Parker MG. Baseline leisure time activity and cognition more than two decades later. Int J Geriatr Psychiatry. 2011;26(1):65-74.

34. Park DC, Lodi-Smith J, Drew L, Haber S, Hebrank A, Bischof GN, Aamodt W. The impact of sustained engagement on cognitive function in older adults: the synapse project. Psychol Sci. 2014;25(1):103-12.

35. Mortimer JA, Ding D, Borenstein AR, DeCarli C, Guo Q, Wu Y, Zhao Q, Chu S Changes in brain volume and cognition in a randomized trial of exercise and social interaction in a community-based sample of non-demented Chinese elders. J Alzheimers Dis. 2012;30(4):757-66.

36. Gow AJ, Corley J, Starr JM, Deary IJ. Which social network or support factors are associated with cognitive abilities in old age? Gerontology. 2013;59(5):454-63.

37. Lovden M, Ghisletta P, Lindenberger U. Social participation attenuates decline in perceptual speed in old and very old age. Psychol Aging. 2005:20(3):423-34

38. Small BJ, Dixon RA, McArdle JJ, Grimm KJ. Do changes in lifestyle engagement moderate cognitive decline in normal aging? Evidence from the Victoria longitudinal study. Neuropsychology. 2012;26(2):144-55.

39. Golden J, Conroy RM, Lawlor BA. Social support network structure in older people: underlying dimensions and association with psychological and physical health. Psychol Health Med. 2009;14(3):280-90.

40. McHugh JE, Kenny RA, Lawlor BA, Steptoe A, Kee F. The discrepancy between social isolation and loneliness as a clinically meaningful metric: findings from the Irish and English longitudinal studies of ageing (TILDA and ELSA). Int J Geriatr Psychiatry. 2016; epub ahead of print

41. Scarmeas N, Stern Y. Cognitive reserve and lifestyle. J Clin Exp Neuropsychol. 2003;25(5):625-33.

42. Stern Y. What is cognitive reserve? Theory and research application of the reserve concept. J Int Neuropsychol Soc. 2002;8(3):448-60.

43. Steffener J, Stern Y. Exploring the neural basis of cognitive reserve in aging. Biochim Biophys Acta. 2012;1822(3):467-73.

44. Cohen S, Wills TA. Stress, social support, and the buffering hypothesis. Psychol Bull. 1985;98(2):310-57

45. Umberson D. Family status and health behaviours: social control as a dimension of social integration. J Health Soc Behav. 1987;28(3):306-19.

46. Adolphs R. Cognitive neuroscience of human social behaviour. Nat Rev Neurosci. 2003;4(3):165-78

47. Luethi M, Meier B, Sandi C. Stress effects on working memory, explicit memory, and implicit memory for neutral and emotional stimuli in healthy men. Front Behav Neurosci. 2008;2:5.

48. Lupien SJ, McEwen BS, Gunnar MR, Heim C. Effects of stress throughout the lifespan on the brain, behaviour and cognition. Nat Rev Neurosci. 2009; 10(6):434-45.

49. Latkin CA, Knowlton AR. Social network assessments and interventions for health behavior change: a critical review. Behav Med. 2015;41(3):90-7.

50. Cornwell EY, Waite L. Measuring social isolation among older adults using multiple indicators from the NSHAP study. J Gerontol Ser B Psychol Sci Soc Sci. 2009;64(Suppl 1):i38-46.

51. Cacioppo JT, Hawkley LC. Perceived social isolation and cognition. Trends Cogn Sci. 2009;13(10):447-54.

52. Bielak AA. How can we not 'lose it' if we still don't understand how to 'use it'? Unanswered questions about the influence of activity participation on cognitive performance in older age-a mini-review. Gerontology. 2010;56(5):507-19.

53. Brown $C L$, Gibbons LE, Kennison RF, Robitaille A, Lindwall M, Mitchell MB, Shirk SD, Atri A, Cimino CR, Benitez A, et al. Social activity and cognitive functioning over time: a coordinated analysis of four longitudinal studies. J Aging Res. 2012;2012:287438.

54. Ruthirakuhan M, Luedke AC, Tam A, Goel A, Kurji A, Garcia A. Use of physical and intellectual activities and socialization in the management of cognitive decline of aging and in dementia: a review. J Aging Res. 2012; 2012:384875.

55. Martin M, Clare L, Altgassen AM, Cameron MH, Zehnder F. Cognition-based interventions for healthy older people and people with mild cognitive impairment. Cochrane Database Syst Rev. 2011;(1):CD006220. doi:10.1002/ 14651858.CD006220.pub2. 
56. Loughrey DG, Lavecchia S, Brennan S, Lawlor BA, Kelly ME. The impact of the Mediterranean diet on the cognitive functioning of healthy older adults: a systematic review and meta-analysis. Adv Nutr. 2017;8(4):571-86.

57. Pitkala $\mathrm{KH}$, Routasalo $\mathrm{P}$, Kautiainen $\mathrm{H}$, Sintonen $\mathrm{H}$, Tilvis RS. Effects of socially stimulating group intervention on lonely, older people's cognition: a randomized, controlled trial. Am J Geriatr Psychiatry. 2011;19(7):654-63.

58. Chen TY, Chang HY. Developmental patterns of cognitive function and associated factors among the elderly in Taiwan. Sci Rep. 2016;6:33486.

59. Marioni RE, Proust-Lima C, Amieva H, Brayne C, Matthews FE, Dartigues JF, Jacqmin-Gadda H. Cognitive lifestyle jointly predicts longitudinal cognitive decline and mortality risk. Eur J Epidemiol. 2014;29(3):211-9.

60. Plehn K, Marcopulos BA, McLain CA. The relationship between neuropsychological test performance, social functioning, and instrumental activities of daily living in a sample of rural older adults. Clin Neuropsychol. 2004;18(1):101-13.

61. Beland F, Zunzunegui MV, Alvarado B, Otero A, Del Ser T. Trajectories of cognitive decline and social relations. J Gerontol B Psychol Sci Soc Sci. 2005; 60(6):P320-p330.

62. Bosma H, van Boxtel MP, Ponds RW, Jelicic M, Houx P, Metsemakers J, Jolles J. Engaged lifestyle and cognitive function in middle and old-aged, non-demented persons: a reciprocal association? Z Gerontol Geriatr. 2002;35(6):575-81.

63. Glei DA, Landau DA, Goldman N, Chuang YL, Rodriguez G, Weinstein M. Participating in social activities helps preserve cognitive function: an analysis of a longitudinal, population-based study of the elderly. Int J Epidemiol. 2005;34(4):864-71.

64. Hsu HC. Does social participation by the elderly reduce mortality and cognitive impairment? Aging Ment Health. 2007;11(6):699-707.

65. Iwasa H, Yoshida Y, Kai I, Suzuki T, Kim H, Yoshida H. Leisure activities and cognitive function in elderly community-dwelling individuals in Japan: a 5 year prospective cohort study. J Psychosom Res. 2012;72(2):159-64.

66. James BD, Wilson RS, Barnes LL, Bennett DA. Late-life social activity and cognitive decline in old age. J Int Neuropsychol Soc. 2011;17(6):998-1005.

67. Kimura D, Takeda T, Ohura T, Imai A. Evaluation of facilitative factors for preventing cognitive decline: A 3-year cohort study of community intervention. Psychogeriatrics. 2017;17(1):9-16. doi:10.1111/psyg.12182.

68. Lee Y, Kim J, Back JH. The influence of multiple lifestyle behaviors on cognitive function in older persons living in the community. Prev Med. 2009;48(1):86-90.

69. Lee SH, Kim YB. Which type of social activities may reduce cognitive decline in the elderly?: a longitudinal population-based study. BMC Geriatr. 2016; 16(1):165.

70. Tomioka K, Kurumatani N, Hosoi H. Social Participation and Cognitive Decline Among Community-dwelling Older Adults: A Community-based Longitudinal Study. J Gerontol B Psychol Sci Soc Sci. 2016. https://doi.org/ 10.1093/geronb/gbw059.

71. Mousavi-Nasab SMH, Kormi-Nouri R, Nilsson L-G. Examination of the bidirectional influences of leisure activity and memory in old people: dissociative effect on episodic memory. Br J Psychol. 2014;105(3):382-98.

72. Bourassa KJ, Memel M, Woolverton C, Sbarra DA. Social participation predicts cognitive functioning in aging adults over time: comparisons with physical health, depression, and physical activity. Aging Ment Health. 2017; 21(2):133-46.

73. de Frias CM, Dixon RA. Lifestyle engagement affects cognitive status differences and trajectories on executive functions in older adults. Arch Clin Neuropsychol. 2014;29(1):16-25

74. Zunzunegui MV, Alvarado BE, Del Ser T, Otero A. Social networks, social integration, and social engagement determine cognitive decline in community-dwelling Spanish older adults. J Gerontol B Psychol Sci Soc Sci. 2003;58(2):S93-S100

75. Ho SC, Woo J, Sham A, Chan SG, Yu AL. A 3-year follow-up study of social, lifestyle and health predictors of cognitive impairment in a Chinese older cohort. Int J Epidemiol. 2001;30(6):1389-96.

76. Hughes TF, Andel R, Small BJ, Borenstein AR, Mortimer JA. The association between social resources and cognitive change in older adults: evidence from the Charlotte County healthy aging study. J Gerontol B Psychol Sci Soc Sci. 2008;63(4):P241-p244.

77. Wilson RS, Boyle PA, James BD, Leurgans SE, Buchman AS, Bennett DA. Negative social interactions and risk of mild cognitive impairment in old age. Neuropsychology. 2015;29(4):561-70.

78. Andrew MK, Rockwood K. Social vulnerability predicts cognitive decline in a prospective cohort of older Canadians. Alzheimers Dement. 2010;6(4):319-25. e311
79. Windsor TD, Gerstorf D, Pearson E, Ryan LH, Anstey KJ. Positive and negative social exchanges and cognitive aging in young-old adults: differential associations across family, friend, and spouse domains. Psychol Aging. 2014; 29(1):28-43.

80. Shankar A, Hamer M, McMunn A, Steptoe A. Social isolation and loneliness: relationships with cognitive function during 4 years of follow-up in the English longitudinal study of ageing. Psychosom Med. 2013;75(2):161-70.

81. Nelson LA, Noonan CJ, Goldberg J, Buchwald DS. Social engagement and physical and cognitive health among American Indian participants in the health and retirement study. J Cross Cult Gerontol. 2013;28(4):453.

82. McGue M, Christensen K. Social activity and healthy aging: a study of aging Danish twins. Twin Res Hum Genet. 2007;10(2):255-65.

83. Lee T, Lipnicki DM, Crawford JD, Henry JD, Trollor JN, Ames D, Wright MJ, Sachdev PS. Leisure activity, health, and medical correlates of neurocognitive performance among monozygotic twins: the older Australian twins study. J Gerontol B Psychol Sci Soc Sci. 2014;69(4):514-22.

84. Meyer ML, Lieberman MD. Social working memory: neurocognitive networks and directions for future research. Front Psychol. 2012;3:571.

85. Ozbay F, Johnson DC, Dimoulas E, Morgan CA, Charney D, Southwick S. Social support and resilience to stress: from neurobiology to clinical practice. Psychiatry (Edgmont). 2007:4(5):35-40.

86. Charney DS. Psychobiological mechanisms of resilience and vulnerability: implications for successful adaptation to extreme stress. Am J Psychiatry. 2004:161(2):195-216.

87. Southwick SM, Vythilingam M, Charney DS. The psychobiology of depression and resilience to stress: implications for prevention and treatment. Annu Rev Clin Psychol. 2005;1:255-91.

88. Sims RC, Hosey M, Levy S-A, Whitfield KE, Katzel LI, Waldstein SR. DISTINCT FUNCTIONS OF SOCIAL SUPPORT AND COGNITIVE FUNCTION AMONG OLDER ADULTS. Exp Aging Res. 2014;40(1):40-59.

89. McHugh JE, Lee O, Aspell N, Connolly L, Lawlor BA, Brennan S. Peer volunteer perspectives following a complex social cognitive intervention: a qualitative investigation. Int Psychogeriatr. 2016;28(9):1545-54.

90. Ayalon L, Shiovitz-Ezra S, Roziner I. A cross-lagged model of the reciprocal associations of loneliness and memory functioning. Psychol Aging. 2016;31:255

91. Hastings EC, West RL. Goal orientation and self-efficacy in relation to memory in adulthood. Neuropsychol Dev Cogn B Aging Neuropsychol Cogn. 2011;18(4):471-93.

92. Kelly ME, Lawlor BA, Coen RF, Robertson $\mathbb{H}$, Brennan S: Cognitive rehabilitation for early stage Alzheimer's disease: a pilot study with an Irish population. Ir J Psychol Med. 2017:1-15. doi:10.1017/ipm.2017.23.

93. Carstensen LL. Social and emotional patterns in adulthood: support for socioemotional selectivity theory. Psychol Aging. 1992;7(3):331-8.

94. Valtorta N, Hanratty B. Loneliness, isolation and the health of older adults: do we need a new research agenda? J R Soc Med. 2012;105(12):518-22.

95. Cattan $M$, White $M$, Bond J, Learmouth A. Preventing social isolation and Ioneliness among older people: a systematic review of health promotion interventions. Ageing Soc. 2005;25(01):41-67.

96. Masi CM, Chen HY, Hawkley LC, Cacioppo JT. A meta-analysis of interventions to reduce loneliness. Personal Soc Psychol Rev. 2011;15(1):219-66.

97. Hannigan C, Carney S, McHugh JE, Lawlor BA. More than a phone call: an evaluation of the good morning service, Donegal.In. Trinity College Dublin: Dublin; 2015.

98. Cohen S. Psychosocial models of the role of social support in the etiology of physical disease. Health Psychol. 1988;7(3):269-97. 